\title{
Princípios Do Equador E Autorregulação Mundial: Reflexos E Influências Da Governança Global No Direito Interno Brasileiro
}

\author{
Deilton Ribeiro Brasil,
}

Pós-doutor em Direito pela Università degli Studi di Messina, Itália. Professor da Graduação e do PPGD - Mestrado em Proteção dos Direitos Fundamentais da Universidade de Itaúna-MG e das Faculdades Santo Agostinho-FASA. E-mail: deilton.ribeiro@terra.com.br

\section{Leonardo Alexandre Tadeu Constant de Oliveira}

Mestrando em Proteção dos Direitos Fundamentais do PPGD, da Universidade de Itaúna-MG. E-mail: leonardoconstant@hotmail.com

\section{Patrick Juliano Casagrande Trindade}

Mestrando em Proteção dos Direitos Fundamentais do PPGD, da Universidade de Itaúna-MG. E-mail: patrick.casagrande@hotmail.com

Resumo: A nova ordem mundial refletida pela globalização e influenciada pelos direitos humanos implicou no estabelecimento de novos atores que ao lado dos Estados passaram a conduzir seus rumos. Atualmente os governos buscam efetividade ao mesmo tempo que convivem com outros níveis de poder global, fato que requer aliar medidas oficiais e privadas de normatividade, como na autorregulação. Estes conceitos são abordados neste artigo, pelo método dedutivo e procedimento teórico-histórico e analítico-interpretativo, visando discutir seus impactos sob a perspectiva da governança global, partindo dos Princípios do Equador editados pelos Bancos Internacionais e da normatização ambiental do BACEN, em busca da efetividade. A pesquisa é de natureza teórico-bibliográfica seguindo o método descritivo-dedutivo que instruiu a análise da legislação, bem como a doutrina que informa os conceitos de ordem dogmática.

Palavras-chave: Princípios do Equador. Governança Global. Autorregulação. Direitos humanos. Meio ambiente.

\section{UNIVERSIDADE FEDERAL DA PARAÍBA}




\section{Princípios Do Equador E Autorregulação Mundial: Reflexos E Influências Da Governança Global No Direito Interno Brasileiro}

Deilton Ribeiro Brasil,

Leonardo Alexandre Tadeu Constant de Oliveira

Patrick Juliano Casagrande Trindade

1 INTRODUÇÃO

O reconhecimento do triunfo capitalista pós-guerra fria, num mundo já marcado pelos horrores das Grandes Guerras e pela posterior bipolaridade daquele conflito, foi envolvido pela afirmação da globalização especialmente a partir dos anos 1990, e pelo estabelecimento de novos e poderosos atores internacionais, elevados ao nível dos Estados. Desta forma, a força do capital consolidou as Organizações Internacionais e mesmo determinou arranjos econômicos e proporcionou às Empresas e Bancos Internacionais o papel decisivo de atuar conjuntamente aos Estados nos processos normativos, como verdadeiras forças transnacionais. 
Por outro lado, a afirmação dos Direitos Humanos e o surgimento do Direito Ambiental também no pós-guerra criaram uma condição determinante de atuação dos Estados modificando e flexibilizando a conotação econômica exclusivamente desenvolvimentista. O "surgimento" do ser humano e do planeta como bens tutelados pelo Estado Constitucional, financiado pela economia capitalista, proporciona/requer o surgimento de novas formas de administração pública, bem como proporciona o estabelecimento de uma nova dinâmica legislativa, partindo da própria entidade privada, a autorregulação.

O presente trabalho visa a destacar as iniciativas de autorregulação a partir dos novos atores globais, surgidos no decorrer do período pós-guerra e amplamente revelados com o que se convencionou chamar de globalização. Estes novo atores internacionais passaram paulatinamente a atuar no cenário mundial no nível dos Estados, promovendo um rearranjo administrativo/legislativo sem precedentes e estabelecendo uma verdadeira (e nova) ordem mundial, globalizada e dinâmica, ao mesmo tempo em que carente e dependente de todos os entes globais na consecução de seus fins e na manutenção de sua precária estabilidade.

Neste sentido, o presente artigo parte de uma análise específica de um dos reflexos da opção desenvolvimentista (e capitalista) que é a valorização do próprio capital e da formação de um sistema financeiro mundial, especialmente considerando importância das organizações financeiras e sua atuação nos projetos do setor público ou mesmo nos empreendimentos que impactam as atividades do setor público inerentes a tutela do meio ambiente, enquanto bem mundial e direito humano indiscutível.

A edição dos Princípios do Equador é indiscutivelmente uma manifestação privada de autorregulação advinda do reconhecimento do poder global das entidades financeiras e que marcam uma tutela 
do meio ambiente ao mesmo tempo que demonstra o poder destas instituições como atores no âmbito da governança global.

Partiu-se para tanto e exemplificativamente dos Princípios do Equador enquanto norma de autorregulação internacional e exclusivamente privada, sendo utilizada como paradigma a regulação promovida pelo Banco Central do Brasil (BACEN) pelas Resoluções $\mathrm{n}^{0} 4327 / 14$ e $\mathrm{n}^{\mathrm{o}} 3545 / \mathrm{o} 8$ do CMN/BACEN, que objetivam, como estes, a tutela do meio ambiente e estabelecem diretrizes de defesa ambiental de forma oficial.

O presente artigo teve o desenvolvimento dividido em quatro partes, além da introdução e das considerações finais. Assim o primeiro item do desenvolvimento consiste em uma contextualização histórica imprescindível a compreensão dos institutos tratados no seu bojo. $\mathrm{O}$ segundo item trata da globalização vinculada à economia capitalista e forma com o primeiro item a base fática do desenvolvimento do artigo, uma vez que determina o rearranjo das forças econômicas mundiais e implica no estabelecimento destes novos atores.

A partir da terceira parte do desenvolvimento abordaram-se os Princípios do Equador enquanto manifestação normativa privada de autorregulação, com a quarta, e última parte do desenvolvimento, centrada no reflexo regulatório específico dos Princípios do Equador, enquanto ato autorregulatório e seus reflexos na regulação oficial brasileira, representada pelas Resoluções do BACEN abordadas.

Foi utilizada a pesquisa teórico-bibliográfica, considerando as publicações sobre o tema, especialmente livros e artigos científicos, nos quais se buscou basear as construções históricoevolutivas, a inciativa e reconhecimento da força dos entes privados e o enfraquecimento do poder decisório estatal e formação de um conceito governança como arranjo eficiente-eficaz de decisão e resultado por parte dos administradores. 
Princípios Do Equador E Autorregulação Mundial: Reflexos...

$\mathrm{O}$ artigo vale-se do método dedutivo, partindo-se de uma premissa global e ampla de governança chegando a uma de suas facetas específicas que é a autorregulação, para posteriormente adentrar num de seus exemplos típicos (no caso os Princípios do Equador), e num segundo grau de refinamento abordando num breve estudo comparativo a efetividade dos referidos Princípios (Globais) e suas consequenciais na regulação brasileira, num breve contraponto entre esta forma de autorregulação e a regulação do BACEN.

Além do procedimento técnico teórico, a pesquisa valeu-se da análise histórica de desenvolvimento dos institutos a partir dos arranjos geopolíticos mundiais, bem como da modificação dos valores humanos pós-segunda guerra mundial.

Ao final foram apontadas algumas considerações a respeito dos temas abordados a partir do referencial teórico, especialmente sobre a governança e a autorregulação e sua efetividade e a necessidade de alinhamento a regulação estatal.

\section{O ESTABELECIMENTO DE UMA NOVA ORDEM MUNDIAL E A IMPORTÂNCIA DOS NOVOS ATORES}

Diferentemente da Liga das Nações fundada após a Segunda Guerra Mundial e todo o aparato mundial de equilíbrio de poder que permeou o período entre a 1919 e 1939 e que desembocou na Segunda Guerra Mundial, a Organização das Nações Unidas edificada em 1945 alcançou uma notável estabilidade e alguma preponderância nas decisões exatamente porque foi edificada numa base de poderio militar-político, mas primordialmente econômico. A ONU se tornou um grande palco mundial (ARENDT, 1989). 
Neste viés, a partir do Plano Marshall e da recuperação econômica Europeia, se inaugura uma proposta desenvolvimentista, rapidamente adotada pela Comunidade Internacional de Estados. A ordem econômica prevaleceria sobre a atitude imperialista e mesmo sobre a corrida armamentista que perdurou no cenário mundial, inaugurando uma nova era de paz e de busca por desenvolvimento econômico.

Esta majoração da ordem econômica redundou em diversos aspectos da sociedade mundial, que serão adiante examinados, mas culminou num objetivo velado e ainda maior que a própria Guerra Fria que se passou desde então: a disputa mundial jamais seria a mesma e os impérios territoriais e seus consectários seriam esquecidos, e, consequentemente, a chance de paz se tornou viável, ainda que a paz apenas como oposto da guerra.

Este fascinante assunto não passa de um plano de fundo e não merece ser aqui aprofundado senão para destacar nestes poucos parágrafos a transformação que passou a ordem mundial em seu nível interestatal, especialmente em dois aspectos: o surgimento, a afirmação e a atuação crescente e inquestionável de novos atores supranacionais que modificaram para sempre a forma de se pensar a Política, a Economia e o Direito Internacionais; e a afirmação dos impactos extraterritoriais das ações destes atores de forma inquestionável na forma da chamada globalização.

Por estes dois aspectos, é possível se verificar que a partir da ONU criou-se uma espécie de interesse mundial crescente, ao mesmo tempo em que a ONU atuou e atua hodiernamente no fomento e fiscalização dos objetivos de desenvolvimento mundial, realizando o seu primário objetivo de paz mundial ao mesmo tempo em que ainda hoje se busca o desenvolvimento das nações, já não tão desenvolvimentista como de início, especialmente pelo surgimento das componentes sociais (notadamente a partir dos Direitos Humanos) e ambientais (especialmente a partir das convenções internacionais). 
Assim, para fins de encerramento desta contextualização histórica, parte-se de um contexto de guerra fria, descolonização e busca pela paz através do desenvolvimento que marcou os anos de 1946 a 1960, com a inserção da questão social dos direitos humanos em 1966 e da questão ambiental em 1972, respectivamente ano da edição dos Pactos pelos Direitos Humanos e pela Convenção de Estocolmo, com construção e reconhecimento em 1986 do direito ao desenvolvimento, como direito humano reconhecido pela $\mathrm{ONU}$.

Com o desmoronamento do comunismo soviético em 1989-91, coincidentemente com o formal início da chamada globalização, que marcou as décadas de 1990 e 2000, exacerba-se o triunfo capitalista ao mesmo tempo em que se verifica o surgimento (ou desvelamento) dos novos atores mundiais, especialmente as Organizações Não Governamentais e as Empresas Transnacionais (DOUZINAS, 2009).

Este novo mundo é o que nos interessa, pois é nele que o velho Estado de Bodin e da concepção westfaliana está inserido e é nele que luta para existir, para confirmar ou compartilhar sua soberania, seu império, é neste novo mundo que os Direitos Sociais se misturam ao meio ambiente e a economia capitalista numa dúbia e instável união de individualismo e socialismo (FURTADO, 1998).

$\mathrm{E}$ é neste novo mundo que finalmente as iniciativas privadas vêm opor, desvirtuar ou agregar ao Estado um novo tipo de Poder mundial ou, melhor, uma nova forma em edificação de governar, a governança global, a partir da constatação de que o espaço legislativo estatal agora não é mais exclusivo, havendo novos atores a serem considerados, bem como ambiciosas reivindicações sociais a serem atendidas.

\footnotetext{
${ }^{1}$ A Declaração sobre o Direito ao Desenvolvimento foi adotada pela Resolução ${ }^{0}$
} 41/128 da Assembleia Geral das Nações Unidas, de 4 de dezembro de 1986. 


\section{DESENVOLVIMENTO ECONÔMICO E OS FENÔMENOS DO ÊXITO CAPITALISTA: A GLOBALIZAÇÃO, A GOVERNANÇA GLOBAL E O EMPODERAMENTO DAS ORGANIZAÇÕES FINANCEIRAS}

Diante do êxito capitalista, a comunidade internacional viu, em pouco mais de 25 anos, aquilo que se avizinhava há bem mais tempo: o surgimento de forças mundiais muito além do poder dos Estados. Efetivamente, a busca pela paz posterior a 1945 desembocou num mundo conceitualmente diferente num curto espaço de tempo, já que a busca por poderio militar e territorial foi definitivamente superada pela busca por desenvolvimento tecnológico e pelo sucesso econômico.

Nestes dois aspectos o Estado e sua burocracia são crianças se comparados às empresas privadas, que desde sempre foram os reais financiadores das pesquisas e detentoras do capital, além do precioso know-how administrativo. Seguiu-se a um crescente (e esperado) empoderamento das empresas e bancos internacionais como agentes da geopolítica e economia internacional.

A partir do triunfo capitalista sobre o totalitarismo e depois sobre o comunismo implicou no próprio enfraquecimento do Estado, agora acostado pelas Empresas e Organizações Internacionais, as mesmas que permitiram a sua vitória. $O$ fim da experiência comunista apenas consumou e especialmente acelerou um processo no qual os Estados passaram a conviver com as Grandes Corporações Econômicas no governo mundial (CANOTILHO, 2003).

De fato, a consolidação dos novos atores internacionais ao lado do Estado se revela como um movimento incontrolável e a força destes novos entes cria impactos de diversas formas na organização e 
na administração dos Estados, com a relação de interdependência marcada, especialmente nos últimos anos pela globalização.

Para além de sua preponderante vertente econômica, a globalização possui um multifacetado perfil, pelo qual os padrões de comportamento social, consumo e ideologias transcendem fronteiras. O tráfego de informações, propaganda e comunicação atingiram pela globalização, níveis elevados em pouquíssimo tempo, literalmente transformando o mundo. Não se fala em equilíbrio e estabilidade, mas em mudança contínua, desde os gostos e adoção de costumes até a transferência de instantânea de capitais.

O aumento da articulação social impulsionado pela globalização acaba por fragilizar o Estado Clássico, fazendo com que se repense a sua posição e seu papel, de certa forma em pleno retrabalho na atualidade. A incerteza gerada por este fenômeno global torna a atuação do Estado mais conciliadora que dominadora, ante as evidentes dependências dos grandes capitais e das populações, já que atua numa situação sempre desconfortável e com desafios e escolhas que implicam atendimento as necessidades e sustentação de posições.

A globalização, enquanto fenômeno multidimensional promove um deslocamento do poder (ou demonstra este deslocamento) de forma a exigir uma interação global, com a inevitável modificação dos conceitos clássicos de Estado, especialmente do poder soberano, exigindo uma forma de poder expressa de maneira diferente, um governo, ou uma governança global, seja pelo surgimento de espaços de poder preenchidos pelas Organizações Não Governamentais e pelas Transnacionais ou mesmo por estes criados, afastando ou cooptando o poder do Estado (MIALHE, 2003).

O modelo de instituições ocidentais tem sido preponderante e sua citação neste último parágrafo serve apenas para não se descurar do claro objetivo de discussões em planos democráticos nestes mesmos moldes, uma vez que o motor da globalização capitalista 
ocidental não pode ignorar a diversidade cultural mundial esculpida pela evolução dos seres humanos nos últimos 5000 mil anos, da mesma forma que não se pode ignorar a preponderância e os desafios que implicaram na adoção de padrões ocidentais na edificação do pacto de direitos humanos de 1948 e dos tratados dele advindos em 1966.

Nunca mais um Estado estará solitário para decidir sobre seus destinos, políticas e realizações, já que inserido numa ordem mundial globalizada, tem sua governabilidade influenciada por uma governança internacional, estabelecida por todos os atores, especialmente Estados de capitalismo desenvolvido e empresas transnacionais.

O Banco Mundial referiu-se a governança como uma administração voltada para garantia de eficiência de um Estado, afastando-se do império estatal e voltando-se para uma capacidade administrativa capaz de obter resultados não apenas econômicos, mas sociais e ambientais, que refletem a forma pela qual o governo exerce o seu poder.

Sob este enfoque, a avaliação da governança é relativamente simples, especialmente se voltada a um governo específico, porém ao se falar em governança global, deve se ter em mente os atores não estatais elencados, o que torna a governabilidade mais delicada (ANDRADE; ROSSETI, 2011).

A governança global, nesta esteira, abarcaria estas atribuições de articulação e cooperação através de arranjos no âmbito da comunidade internacional, entre todos os seus atores, estatais ou não. Trata-se de um conceito mais amplo, de articulação e cooperação entre os atores políticos, sociais e nos arranjos institucionais que coordenam e regulam transações para além dos limites do sistema econômico-social (CASADO FILHO, 2011).

A flexibilização do poder estatal, iniciada a partir da força desenvolvimentista, da ONU, do estabelecimento de novos atores 
Princípios Do Equador E Autorregulação Mundial: Reflexos...

internacionais e da globalização redundou numa divisão de poderes não prevista no clássico modelo de Estado, cujo poder seria soberano e incontestável. Este poder incontrastável esbarrou nas medidas econômicas colidentes com as Constituições e seus objetivos não financiáveis pelos tributos.

As tradicionais manifestações do poder estatal por medidas normativas, inicialmente as Leis e regulamentações e finalmente a regulação (especialmente a partir das privatizações das empresas estatais, posteriores aos estados sociais), culminaram com a autorregulação promovida pelos próprios atores internacionais, das quais se observam impactos nas próprias normas estatais e na sua administração, notadamente no setor financeiro.

\section{A NOVA ORDEM ECONÔMICA, A EDIÇÃO DOS PRINCÍPIOS DO EQUADOR E SUA AUTORREGULAÇÃO}

O surgimento de uma governança global é um fenômeno que pode ser representado pelas diversas iniciativas em âmbito internacional pelos atores não estatais para a consecução de objetivos mundiais, notadamente as Organizações Não Governamentais de finalidade assistente-social e ambiental e também pelas Transnacionais, como as grandes organizações comerciais, industriais e financeiras.

A força das instituições financeiras como atores de primeira grandeza no cenário internacional acompanhou o objetivo de desenvolvimento econômico desde o Plano Marshall e imbricou a ONU desde o seu nascedouro, com a criação do Banco Mundial e do Fundo Monetário Internacional - FMI. E desde então os 
financiamentos dos grandes empreendimentos dos Estados contaram com recursos deste tipo de instituição, sendo os conglomerados econômicos desde então criados em torno de bancos.

Nesta esteira, as decisões destes atores, tal qual anteriormente apenas aos Estados caberiam, produzem impactos profundos nas decisões dos poderes públicos estabelecidos, cabendo sua normatização enquanto Instituições globais aos próprios Estados, mas também a elas mesmas, uma vez que a Governança Global implica num elaborado feixe de decisões que tendem a aperfeiçoar ganhos a todos os atores, ao menos num espaço público de discussão e publicidade, com o devido respeito ao desenvolvimento econômico, social e ambiental.

E imbuídos deste espírito e ao mesmo tempo em que motivados pelo Banco Mundial, surgiram os Princípios do Equador, a partir do consenso feito em 2003 por 10 instituições financeiras de âmbito global, nomeadamente - ABN Amro, Barclays, Citigroup, Crédit Lyonnais, Crédit Suisse, HypoVereinsbank (HVB), Rabobank, Royal Bank of Scotland, WestLB e Westpac - que criaram uma série de princípios como uma ferramenta voluntária para verificar se os projetos que requeriam financiamento cumpriam as exigências de sustentabilidade, de acordo com critérios estabelecidos pelo Banco Mundial.

Como destacado, tratam-se de princípios de adesão volitiva (soft law) que apesar disso foram rapidamente adotados por diversas outras instituições financeiras, numa iniciativa no sentido de tornar investimentos privados em projetos públicos de grande vulto submetidos a regras adequadamente preconizadas de sustentabilidade.

Os princípios do Equador preconizam medidas a serem atendidas através do cumprimento de requisitos para que sejam concedidos e também fiscalizados financiamentos de projetos. Estas medidas são inerentes a cuidados com o meio ambiente e com as populações atingidas pelos projetos, e implicam em observação às 
Princípios Do Equador E Autorregulação Mundial: Reflexos...

condições de trabalho, aos níveis corretos de poluição e emissões de gases de efeito estufa; à realização de consultas públicas para verificação da viabilidade do projeto.

Constituem um conjunto de medidas que visam respeitar a sociedade em geral, as populações locais e a proteção do meio ambiente, a partir do nascedouro, ou seja, da análise para a concessão do financiamento do projeto pela entidade financiadora, que promove uma análise na qual os projetos são classificados de acordo com o risco social e ambiental que apresentam, e são enquadrados numa das três categorias previstas: A - alto risco, B médio risco e $\mathrm{C}$ - baixo risco.

A avaliação do risco implica no atendimento a mais ou menos itens para a concessão do financiamento, sendo que para os empreendimentos classificados nas categorias A e B, as Instituições Financeiras elaboram um relatório sugerindo mudanças no projeto, de maneira a adequá-los às exigências internacionais socioambientais de forma a garantir-se que haja o cumprimento dos preceitos de proteção à sustentabilidade da forma mais viável possível. Nos empreendimentos de categoria $\mathrm{C}$, pela mínima possibilidade de impacto, uma vez que os impactos ambientais são inexistentes ou irrelevantes, não é exigida nenhuma avaliação ambiental ou medidas mitigadoras específicas.

Após a avaliação, a Instituição Financeira verificará a conformidade do projeto com a lei, as regulamentações e licenças pertinentes do país anfitrião no âmbito socioambiental, estabelecendo padrões aplicáveis para a concessão do crédito com os quais há o compromisso de atendimento contratualmente estabelecido, que será também devidamente fiscalizado em seu cumprimento no decorrer da obra e da concessão contratual do crédito.

Tal exigência representa um ato normativo extra, pois traz força contratualmente cogente às normas do Estado, já que estas foram usadas como padrão para o estabelecimento do contrato e seu 
descumprimento implica em descumprimento contratual. Neste caso, a autorregulação trouxe cogência a norma estatal e tutelou bem difuso e mundial, concernente aos próprios direitos humanos.

E a autorregulação ainda torna mais fiscalizável a execução do empreendimento, considerando que a Instituição Financeira determina que o cliente possua um Sistema de Gestão Ambiental e Social e um Plano de Gestão Socioambiental para lidar com questões surgidas durante o processo de avaliação e para incorporar ações requisitas para que o projeto esteja em conformidade com os padrões aplicáveis tratados no Princípio anterior, inclusive criando mecanismos de reclamação para receber os clamores da comunidade afetada, bem como facilitar a busca de soluções para tais demandas.

Parte-se de um engajamento efetivo do tomador do financiamento com a questão socioambiental do projeto, com respeito as partes interessadas num processo contínuo de diálogo junto às comunidades afetadas, bem como a outras partes interessadas. Para tanto estabelece-se ainda a criação de processos de consultas e participação para os projetos que tiverem potencial de gerar impactos significativos, para que as partes possam ser informadas sobre estes riscos e impactos.

A autorregulação tratada pelos Princípios do Equador determina também que nos projetos com impacto ambiental a exigência de uma análise independente de toda a implementação do procedimento determinado pelos Princípios, a ser realizados por um Consultor Socioambiental Independente, que não esteja ligado ou associado ao cliente.

E também deverá ser feita, de forma independente, a averiguação dos impactos e riscos socioambientais sobre as comunidades envolvidas, seu habitat, patrimônio cultural, reassentamento, além de outras análises, garantindo isenção na apuração dos resultados e de todo o processo. 
Princípios Do Equador E Autorregulação Mundial: Reflexos...

Uma importante ferramenta para a análise e aprovação deste financiamento são as adesões às obrigações contratuais do cliente, através de instrumentos contratuais, que representam o compromisso do cliente em atuar em conformidade com as leis, licenças e regulamentações pertinentes ao país anfitrião, em respeito a legislação interna deste.

A publicidade são ainda outro enorme ganho com a autorregulação pelos Princípios do Equador, com a obrigação contratual de divulgação de informações requeridas aos clientes para toda a comunidade, devendo ser disponibilizando um resumo em canal eletrônico pela internet, com a divulgação anual dos níveis de emissões de gases de efeito estufa durante a fase operacional do projeto, tornando transparente a relação entre as partes interessadas e afetadas.

Ao preconizar engajamento, transparência e respeito às normas no momento da contratação financeira, tem-se efetivamente uma oportunidade de se controlar, desde o começo, o estabelecimento de um projeto de obra potencialmente danoso ao ambiente e a sociedade, sendo uma exemplar forma de controle e um exemplo de benefício que pode ser gerado a partir de um ato autorregulatório.

O estabelecimento dos Princípios do Equador marca um momento de expectativa altamente positiva sobre o estabelecimento de um padrão de investimento internacional social e ambientalmente responsável, exigindo o engajamento e especialmente o respeito a legislação nos contratos de financiamento de projetos com impacto ambiental. 


\section{A AUTORREGULAÇÃO E SEU IMPACTO NO DIREITO INTERNO BRASILEIRO}

Os grandes empreendimentos constituem exemplos clássicos de obras de grande impacto socioambiental, que demandam elevados recursos financeiros, exigindo-se, no momento da sua concessão pelo financiador, o adequado cumprimento de normas ambientais e da implementação de controles preventivos dos possíveis impactos advindos desse empreendimento.

Ante a própria condição dos Estados enquanto entes normativos e das entidades financeiras enquanto atores globais, estabelece-se que a regulação e a autorregulação são iniciativas equiparáveis, uma vez que o capital dos bancos, muitas vezes de países desenvolvidos e com normas rigorosas ambientais podem e devem somar-se a normatividade local.

A autorregulação pelas próprias instituições financeiras e a regulação estatal para a concessão do crédito, com a consideração aos riscos ambientais e sociais possíveis diante do empreendimento a ser realizado, acabam por se complementar, mas carecem ainda de efetividade plena e da força estatal, ainda que diminuída, como ente isento, pelo menos no que tange ao Brasil.

Os Princípios do Equador retratam uma iniciativa privada de regulação, por se tratarem da consolidação, pela iniciativa privada, dos anseios do Banco Mundial, com adesão voluntária pelas demais instituições financeiras, tornando-se um padrão de referência internacional quanto à gestão de riscos sociais e ambientais voltados ao financiamento de grandes empreendimentos.

Decorre daí a necessidade da perfeita concertação das duas normatividades de forma a aperfeiçoar a regulação visando à efetiva aplicabilidade dos Princípios concomitantemente ao atendimento 
Princípios Do Equador E Autorregulação Mundial: Reflexos...

legal. Concertação que deve afinar e melhorar ambos os institutos de forma a dar a efetividade por eles buscada, na tutela de seu louvável objeto.

Um exemplo de falha na concertação é o fato dos Princípios do Equador se aplicarem a apenas alguns tipos de produtos financeiros oferecidos pelas Instituições, o que reduz o montante das operações realizadas, já que este grupo de produtos representam apenas $5 \%$ do total das atividades. Este fato, aliado a aplicação do sigilo bancário, como prerrogativa legal, para dificultar o monitoramento e a fiscalização das atividades dos financiadores e a ausência de sanções formais para o seu descumprimento, demonstram ainda um lado frágil na sua aplicação, quando mais no Brasil cujo próprio Banco Nacional de Desenvolvimento não é aderente aos Princípios (TASSE; MULLER; JÚNIOR, 2015).

O que se revela na prática é que muitas vezes há violação dos Princípios do Equador tanto pelos financiadores quanto pelos tomadores de crédito justamente pela dificuldade de um monitoramento transparente, que deveria partir da Instituição Financeira signatária e que acaba sendo compelido ao Estado, ante ao evidente "conchavo". Assim, e a despeito da inciativa dos Princípios do Equador, verifica-se que ante as práticas das instituições financeiras e dos tomadores de crédito no Brasil, ainda há grande necessidade de ações regulatórias por parte do Estado.

No sentido de estabelecer algum destino melhor a excelente iniciativa dos Princípios, é proposta uma revisão deste modelo regulatório soft law pela vinculação dos Princípios a algum padrão de ordem pública normativo, e não apenas o modelo autorregulador dos Princípios do Equador, e que poderia ensejar proteção mais eficaz quanto aos riscos inerentes desses grandes projetos (CALDAS; MARTINS, 2016).

Neste sentido afigura-se "Indispensável, para uma maior efetividade dos Princípios do Equador (...) que as suas normas de governança corporativa sejam incorporadas ao ordenamento jurídico 
brasileiro como normas gerais regulatórias nas contratações públicas...”, conforme bem destacado por Caldas e Martins (2016).

A Regulação do setor bancário no Brasil é promovida pelo Banco Central do Brasil (BACEN), que é o responsável pelo controle de riscos nas operações financeiras, supervisionando e tornando públicas as deliberações do Conselho Monetário Nacional (CMN) a respeito da política nacional de concessão de crédito.

No que tange as questões abordadas pelos Princípios do Equador e atinentes a regulamentação das questões socioambientais pode ser tida como norma relevante a Resolução n ${ }^{\circ} 3545 / 08$ do CMN/BACEN, que estabelece a exigência de documentação comprobatória de regularidade ambiental para a concessão de crédito (crédito rural) para atividades agropecuárias nos municípios que integram o Bioma Amazônia, uma atitude legisladora que fortalece a autorregulação pelos Princípios do Equador.

Esta norma aumentou a exigência para concessão de crédito com relação a áreas destinadas a atividades agropecuárias na Amazônia, no sentido de tutelar a área de floresta, certificando-se de que os terrenos sejam regularmente constituídos nos Cadastros competentes, criando um nível documental teoricamente capaz de bloquear áreas desmatadas e "griladas" da floresta. A despeito dos resultados em termos de eficiência, tal fato sinaliza a direção, ao menos teórica, na qual regulação e autorregulação devem seguir, especialmente em termos de sinergia e de atuação complementar.

Diferentemente do alcance regional da Resolução 3545/o8, outra norma do Banco Central a se destacar é a Resolução $n^{0}$ 4327/14, que também se relaciona ao risco socioambiental dos financiamentos concedidos pelas instituições financeiras com alcance nacional. Esta Resolução estabelece diretrizes sobre a responsabilidade socioambiental das instituições financeiras ou equivalentes, autorizadas a funcionar neste segmento, ampliando e distribuindo obrigações de prevenção e precaução entre os agentes econômicos. 
Princípios Do Equador E Autorregulação Mundial: Reflexos...

A Resolução 4327/2014 estabelece um vínculo das instituições financeiras aos padrões de gestão socioambiental determinados, determinado que sejam considerados os riscos socioambientais e geridos de forma a estabelecer a governança especifica através de políticas socioambientais ao mesmo tempo que evitar ou minimizar os riscos pela gestão indevida destes riscos. Trata-se de um instrumento técnico de governança corporativa e estabelecimento de padrões de gestão de risco obrigatórios, mas que reconhece o perigo dos danos socioambientais a ponto de incluir na gestão dos contratos.

Deste reconhecimento advém a gestão que, se provada ineficaz ou indevida em sua execução pode sujeitar a Instituição Financeira à responsabilidade civil e ambiental em caso de descumprimento, pela demonstração do nexo causal entre o seu ato e o risco gerado pelo financiamento, que gerou o dano, criando, assim, uma Política de Responsabilidade Socioambiental (YOSHIDA; PIAZZON, 2014).

Ainda se tem por discutível a efetividade destas medidas, ainda que conjuntas, pois a generalidade da Resolução aliada à obscuridade das exigências às instituições financeiras pelos Princípios dificulta a caracterização do risco criado pelo descumprimento da norma por parte da instituição financeira (e a sua sanção, bem como a delimitação do efetivo causador), crítica esta atenuada por se tratar evidentemente de um processo em construção.

A respeito desta ampla possibilidade responsabilização ser possível, dada a própria natureza regulatório da Resolução, seu alcance é notório e demonstra evolução normativa no sentido de tutela efetiva, a partir da regulação bancária, do investimento cada vez mais ecologicamente responsável, de forma a consolidar a sua importância.

A associação das Resoluções do BACEN aos Princípios do Equador cria uma normatização de agentes reguladores oficiais em coordenação com medidas originárias de atores privados, que projeta 
um desenho interessante a tutela socioambiental, indispensável a tutela destes direitos difusos que podem por esta via obter efetiva proteção, na constante evolução da importância destas questões, quer pela iniciativa privada ou pelos entes públicos.

\section{CONSIDERAÇÕES FINAIS}

Ante uma nova ordem mundial na qual a iniciativa de agentes internacionais não estatais pode resolver demandas que os Estados não conseguem, e ainda de forma mais eficiente, conceitos como governança e autorregulação passam a representar formas de garantia de direitos, especialmente no que concerne a questões de grande monta, como a questão ambiental. Desta forma, a edição de normas privadas pode dar eficiência e mesmo promover a obtenção de resultados que resguardem os Direitos Humanos, o que representa um grande avanço e um acréscimo aos esforços estatais na sua consecução.

Visando garantir a existência das próprias instituições privadas, da comunidade e do Estado, num ambiente harmônico, os Princípios do Equador são um exemplo dos benefícios que podem advir da autorregulação na tutela dos direitos fundamentais.

A iniciativa dos Princípios do Equador se apoia na capacidade de consenso dos entes privados e ao mesmo tempo acabam por envolver o Estado e a própria comunidade internacional na efetivação de normas protetivas e reguladoras de direitos ambientais, pois sua atuação parte exatamente do comprometimento privado com a defesa do meio ambiente, em uma norma elaborado por quem financia os empreendimentos que podem prejudicá-lo.

Tem-se ainda que os referidos princípios são a demonstração cabal da força do capital privado, indiscutivelmente necessário a execução de empreendimentos públicos e privados de grande porte. Abre-se, reconhecida esta força, a possibilidade do Estado através de 
Princípios Do Equador E Autorregulação Mundial: Reflexos...

ações conjuntas e concertadas, de tornar-se gestor e protagonista conjunto com as forças privadas, de forma a promover o desenvolvimento e ao mesmo tempo proteger o meio ambiente. Tal fato pode ser exemplificado pela própria influência dos princípios do Equador como normas privadas de regulação bancária.

Os Princípios do Equador demonstram a capacidade do ente privado de atuar sem a norma pública, ao mesmo tempo em que a norma pública pode e deve reproduzir o desejo privado, de forma a criar uma sinergia capaz de prover a sociedade em âmbito ao mesmo tempo em que atende aos anseios da comunidade local em prol da sociedade.

Os Estados devem utilizar do poder que lhes resta para paulatinamente se tornar gestores de forças privadas e públicas de forma a posicionar-se com destaque nesta seara, reconhecendo a sua limitação ao mesmo tempo em que incorporando em sua legislação, através de cuidadosa concertação, as iniciativas de normatização privadas, exercendo o poder regulatório em total consonância com a iniciativa privada e sua autorregulação.

A regulação estatal, por sua vez, é de suma importância desde que numa atuação coordenada com a dos entes privados, já que não bastam apenas que esses atores internacionais determinem, de forma volitiva, regras para tal fim, havendo que ser encontrada e apoiada a autorregulação nas normas regulatórias e até mesmo na legislação dos Estados.

A autorregulação pelos Princípios do Equador no Brasil carece de força normativa cogente, embora com sua força relativa e interesse mútuo dos envolvidos, fragiliza-se tanto no seu cumprimento quanto na possibilidade de responsabilização pelos danos ou riscos causados pelo projeto financiado, pois necessita de força harmonizada na legislação, dado que a sociedade brasileira é marcada pela maciça presença estatal.

Desta forma, para transpor a barreira de modelo regulatório soft law e chegar-se a vinculação normativa de lei, ainda que se trata 
de norma privada, há que se articular a vinculação de normas como os Princípios do Equador a um padrão normativo de ordem pública regulador, de forma a aumentar a efetiva proteção, especialmente se tratando de financiamento de projetos de ordem pública e de grande porte.

Outro argumento para a vinculação de normas privadas de regulação, pela autorregulação às normas públicas, seria o de fortalecimento do Estado como ente fiscalizador e como beneficiário dos contratos, já que ao dispor das normas emanadas do setor privado e dotando-as de força pública recupera seu prestígio decisório e alia-se aos entes poderosos que surgiram deste fenômeno histórico de globalização econômica. O contrário seria a negativa e a sobrecarga dos sistemas econômicos e o enfraquecimento dos poderes do Estado, com esvaziamento do poder normativo, desprestigiam do executivo e inocuidade do legislativo e, por fim, a sobrecarga do judiciário.

A atuação dos Bancos Centrais tem sido determinante nos aspectos econômicos e sociais dos países, sendo que a leitura e a correta incorporação pela legislação regulatória das normas de autorregulação pode ser um trunfo real na defesa dos direitos humanos, ao mesmo tempo em que uma forma do Estado recuperar parte de seu protagonismo, obtendo efetividade em direitos que cada dia se tornam mais difíceis de tutelar, mas que não deixam de fazer parte sua atribuição constitucional.

Num mundo no qual cada vez mais o capitalismo e sua força decidem, que a globalização impõe a ordem e estabiliza (ou não) novos conceitos, o Estado precisa se reinventar enquanto poder e ao invés de estipular o que deve ou não deve ser pelo peso da Lei, passa a gerir a iniciativa privada e administrar as normas que o próprio ente privado, em sua disputa mercadológica produz.

O reconhecimento da atuação dos novos atores é elemento indissociável de um novo mundo, no qual espera, haja maior comprometimento do Estado, agora cercado por outros atores tão 
Princípios Do Equador E Autorregulação Mundial: Reflexos...

poderosos quanto ele, com as políticas públicas as quais marcaram a sua criação para as quais invariavelmente deu às costas, de forma a se conscientizar, num plano mundial, um governo de divisão de riscos com uma opinião pública atenta e participativa.

Data de Submissão: 23/03/2018

Data de Aprovação: 19/07/2018

Processo de Avaliação: double blind peer review

Editor Geral: Jailton Macena de Araújo

Editor de Área: Jailton Macena de Araújo

\section{REFERÊNCIAS}

ANDRADE, Adriana; ROSSETTI, José Paschoal. Governança corporativa: fundamentos, desenvolvimento e tendências. 5. ed. São Paulo: Editora Atlas, 2011.

ANTUNES, Paulo Bessa; FERNANDES, Elizabeth Alves. Responsabilidade Civil Ambiental de Instituições Financeiras. In: Revista da Procuradoria-Geral do Banco Central, vol. 9, n. 1, pp. 19-50, jun. 2015. 
ARENDT, Hannah. As Origens do totalitarismo. São Paulo: Companhia das Letras, 1989.

BORGES, Caio. Desenvolvimento para as pessoas? O financiamento do BNDES e os direitos humanos. Conectas Direitos Humanos. 1. Ed. São Paulo, 2014. Disponível em: <http://www.conectas.org/arquivos/editor/files/Conectas_BNDES \%20e\%20Direitos\%20Humanos_Miolo_Final_COMPRIMIDO>. Acesso em: 31 mar. 2017.

CALDAS, Roberto Correia da Silva Gomes. O contexto sinérgico das atividades de regulação administrativa concertada à luz dos denominados contratos administrativos. In: Interesse Público, ano 12, $\mathrm{n}^{\mathrm{O}}$ 61, p. 69-82, mai./jun. 2010.

CALDAS, Roberto Correia da Silva Gomes; MARTINS, Thiago Penido. Princípios do Equador e Governança Regulatória nas contratações públicas sustentáveis: implicações nas desapropriações. In: Revista Brasileira de Estudos Políticos, vol. 112, p. 183-230, 2016. Disponível em:

<http://www.pos.direito.ufmg.br/rbep/index.php/rbep/article/view /P.0034-7191.2016V112P183>. Acesso em: 30 mar. 2017.

CANOTILHO, José Joaquim Gomes. Existe um direito constitucional da regulação? In: Revista do Advogado, Ano XXIII, no 73, p. 109111, nov. 2003.

CASADO FILHO, Napoleão. Governança Corporativa: análise jurídica dos seus efeitos. São Paulo: Ed. Conceito Jurídico, 2011.

DOUZINAS, Costas. O fim dos Direitos Humanos. São Leopoldo: Unisinos, 2009.

EPFI's - Equator Principles Financial Institutions (2013). Os princípios do Equador: um referencial do setor financeiro para identificação, avaliação e gerenciamento de riscos socioambientais em projetos. Disponível em: <http://www. equator-principles.com/resources/equator_principles_ portuguese_2013>. Acesso em: 20 mar. 2017.

FURTADO, Celso. O mito do desenvolvimento econômico. 2. ed. São Paulo: Paz e Terra, 1998.

MEDAUAR, Odete. Regulação e autorregulação. In: Revista de direito administrativo, $\mathrm{n}^{0}$ 228, p. 123-128, abr./jun. 2002.

MEIRELLES, Hely Lopes. Direito administrativo brasileiro. 32. ed. São Paulo: Malheiros Editores, 2006.

MIALHE, Jorge Luís. Desafios no ensino do Direito Internacional Público e do Direito da Integração em tempos de globalização. In: 
Princípios Do Equador E Autorregulação Mundial: Reflexos...

Impulso - Revista de Ciências Sociais e Humanas. Direito e globalização, vol. 14, n ${ }^{0}$ 33, p. 85-111, jan./abr. 2003.

MIRANDA, Jorge. Direito Constitucional e Direito Internacional. In: Revista do Advogado, Ano XXIII, nº 73, p. 89-93, nov. 2003.

Normativo SARB $\mathrm{n}^{0}$ 14, de 28 de agosto de 2014. Dispõe sobre a criação e implementação de política de responsabilidade socioambiental. Disponível em:

<http://www.autorregulacaobancaria.org.br/pdf/Normativo\%20SA RB\%20014\%20-\%20Responsabilidade\%20Socioambiental\%20-\%20 aprovado\%20CAR\%2028.08.14>. Acesso em: 05 mar. 2017.

Resolução $n^{0} 4.327$, de 25 de abril de 2014. Dispõe sobre as diretrizes que devem ser observadas no estabelecimento e na implementação da Política de Responsabilidade Socioambiental pelas instituições financeiras e demais institui- ções autorizadas a funcionar pelo Banco Central do Brasil. Disponível em:

<http://www.bcb.gov.br/pre/normativos/res/2014/pdf/res_4327_v 1_O>. Acesso em: 31 mar. 2017.

TASSE, Juliana. MULLER, Juliana Martins de Sá. JUNIOR, Luiz Carlos Silva Faria. A Regulação do financiamento para empreendimentos de risco socioambiental: iniciativas e perspectivas. Revista eletrônica do Centro de Direitos Humanos e Empresas. Disponível em:

$<\mathrm{https}$ ://seminariosinternacionaisdireitoshumanoseempresas.files.w ordpress.com/2015/10/a-regulac3a7c3a3o-do-financiamento-paraempreendimentos-de-risco-socioambiental-iniciativas-eperspectivas-gt-1-id-artigo-completo>. Acesso em: 31 mar. 2017.

YOSHIDA, Consuelo Y. Moromizato; PIAZZON, Renata Soares.

Responsabilidade socioambiental dos bancos. Disponível em: $<$ http://consultaudi.com.br/responsabilidade-socioambiental-dosbancos/>. Acesso em: 31 mar. 2017. 


\title{
Equatorial Principles And Worldwide Self- Regulation: Repercussions And Influences Of Global Governance In Brazilian Domestic Law
}

\author{
Deilton Ribeiro Brasil,
}

\author{
Leonardo Alexandre Tadeu Constant de Oliveira
}

\author{
Patrick Juliano Casagrande Trindade
}

\begin{abstract}
The new world order reflected by globalization and influenced by human rights implied the establishment of new actors that along with the States started to lead their course. Governments are currently seeking effectiveness while coexisting with other levels of global power, a fact that requires allying official and private regulatory measures, such as self-regulation. These concepts are approached in this article, by the deductive method and the theoretical-historical and analytic-interpretative procedure, aiming to discuss their impacts from the perspective of global governance, starting from the Equator Principles issued by the International Banks and the environmental normalization of BACEN, in search of Effectiveness. It's a theoretical-bibliographical-natured research guided by descriptive-deductive method which had instructed the analysis of legislation, as well as the doctrine that informs the concepts of dogmatic order.
\end{abstract}

Keywords: Equator Principles. Global governance. Self-regulation. Human rights. Environment. 